\title{
Effects of cryopreservation on semen quality and the expression of sperm membrane hexose transporters in the spermatozoa of Iberian pigs
}

\author{
S Sancho ${ }^{1,2}$, I Casas ${ }^{1}$, H Ekwall ${ }^{2}$, F Saravia ${ }^{2}$, H Rodriguez-Martinez ${ }^{2}$, J E Rodriguez-Gil ${ }^{3}$, E Flores ${ }^{3}$, \\ E Pinart $^{1}$, M Briz ${ }^{1}$, N Garcia-Gil ${ }^{1}$, J Bassols ${ }^{1}$, A Pruneda $^{1}$, E Bussalleu ${ }^{1}, M$ Yeste $^{1}$ and S Bonet ${ }^{1}$ \\ ${ }^{1}$ Biotechnology of Porcine Reproduction, University of Girona, Campus de Montilivi, s/n, 17071 Girona, Spain, \\ ${ }^{2}$ Division of Comparative Reproduction, Obstetrics and Udder Health, Faculty of Veterinary Medicine and Animal \\ Sciences, Swedish University of Agricultural Sciences (SLU), SE-750 07, Uppsala, Sweden and ${ }^{3}$ Unit of Animal \\ Reproduction, Department of Animal Medicine and Surgery, School of Veterinary Medicine, Autonomous University \\ of Barcelona, Barcelona E-08193, Spain
}

Correspondence should be addressed to S Sancho; Email: silvia.sancho@udg.es

\begin{abstract}
This study evaluated the effects of cooling, freezing and thawing on the plasma membrane integrity, kinetics and expression of two sugar transporters glucose transporter-3 and -5 (GLUT-3 and GLUT-5) in spermatozoa from Iberian boars. Semen samples were collected twice weekly from eight young, fertile Iberian boars of the 'Entrepelado' and 'Lampiño' breeds. The samples were suspended in a commercial extender and refrigerated to $17^{\circ} \mathrm{C}$ for transport to the laboratory (step A), where they were further extended with a lactose-egg yolk-based extender and chilled to $5{ }^{\circ} \mathrm{C}$ (step B) prior to freezing in the presence of glycerol $(3 \%)$. Spermatozoa were assessed for plasma membrane integrity and sperm motility at each of the steps, including post-thaw (step C). Aliquots were also prepared for immunocytochemical localisation of the sugar transporters (fixed and thin smears for transmission and scanning electron microscopy levels respectively) and for SDS-PAGE electrophoresis and subsequent western blotting, using the same antibodies (rabbit anti-GLUT-3 and anti-GLUT-5 polyclonal antibodies). The results showed lower percentages of progressively motile spermatozoa at step $C$ in both breeds, while the percentage of live spermatozoa was significantly lower only in the 'Entrepelado' breed. The results obtained from electron microscopy clearly showed that Iberian boar spermatozoa expressed the hexose transporters, GLUT-3 and GLUT-5. The pattern of expression, in terms of location and concentration, was characteristic in each case but, in the case of isoform GLUT-5, it remained constant during the different steps of freezing-thawing protocol. These results indicate that cryopreservation affects the status of sperm cells of Iberian boars by altering the distribution of some membrane receptors and decreasing the percentage values of parameters linked to sperm quality. Reproduction (2007) $134111-121$
\end{abstract}

\section{Introduction}

In recent years, the development of freezing techniques for semen cryopreservation has become a major resource for the preservation of genetic material in most domestic species (Songsasen \& Leibo 1997a,1997b, Ollero et al. 1998, Colenbrander et al. 2003, Cremades et al. 2005). Although the use of cryopreserved semen for artificial insemination $(\mathrm{Al})$ has spread worldwide on a commercial basis for cattle (Curry et al. 2000), this has not been the case for pigs, where extended semen in liquid form still dominates and $<1 \%$ of frozen semen is used mostly in genetic nuclei or for export (Eriksson \& RodriguezMartinez 2000). Among the reasons for this is the better survival rate, with fertilising capacity intact, of liquid semen that, under farm or farmer Al conditions, provides almost the same prolificacy (number of piglets born) as natural mating. This has enormous sanitary and economic advantages over the more expensive and less fertile frozen-thawed semen.

Moreover, boar spermatozoa suffer extensive membrane and tail damage during cooling and thawing (Watson et al. 1981, Parks \& Graham 1992), and those spermatozoa that survive suffer from a shortened lifespan, requiring Al to be carried out with large numbers of spermatozoa and closely timed to the moment of ovulation (see, for example, Wongtawan et al. 2006). The sensitivity of the boar sperm membranes to cooling 
seems to be strongly related to the characteristic lipid composition of these membranes (Bwanga 1991, Parks \& Lynch 1992, Watson 1995). Focussing on this point, it is worth noting that Pettit \& Buhr (1998) reported that lipid modifications also occur during freezing and thawing, indicating that different domains of the sperm head plasma membrane react differently to cryopreservation. Furthermore, the structural changes produced in the sperm membrane of thawed cells are linked to altered abilities for energy sourcing, which would alter both the housekeeping metabolism of the cell and sperm motility (De Leeuw et al. 1990, Watson 1995, Cerolini et al. 2001). Another sperm alteration linked to cooling/ freezing is related to the transfer of proteins through the cell, which is modulated by the distribution of lipids along the membrane (Parks \& Graham 1992), altering the response to induction of capacitation and the acrosome reaction of frozen/thawed spermatozoa during fertilisation (Guthrie \& Welch 2005).

The characteristic lability of the boar spermatozoon during cooling (Mazur 1963, Pursel et al. 1973, Watson et al. 1981) and the specific lipid composition of its membrane (Holt \& North 1984, Bwanga 1991, Maxwell \& Johnson 1997, Johnson et al. 2000, He et al. 2001) affect its survival post-thaw that, even when proven protocols are used (Westendorf et al. 1975, Bwanga 1991, Eriksson \& Rodríguez-Martínez 2000, Johnson et al. 2000, He et al. 2001, Carvajal et al. 2004, Saravia et al. 2005), still remains sub-optimal. Many attempts have been made to reduce the alterations produced in sperm cells during this process (Breininger et al. 2005, Peña et al. 2005, Saravia et al. 2005, Bathgate et al. 2006), but the results are still far from optimal. Success in the cryopreservation of boar sperm cells might be aided by testing this technique in Iberian pigs, an older breed, which has not been selected for freezability and for which no studies have been reported. Semen conservation of the Iberian boar offers the possibility of preserving genetic variability through biotechnological reproduction programmes. The bottom line is that more insight into the mechanisms underlying cryopreservationrelated boar sperm membrane alterations is still needed.

Another major problem related to cryopreservation is the dislocation of proteins in the plasma membrane, for example those belonging to the glucose transporter (GLUT) family. These GLUT proteins, as a whole, are mainly responsible for the transport of hexose across mammalian sperm membranes (Burant et al. 1992, Farooqui et al. 1997, Angulo et al. 1998, Kokk et al. 2005). GLUT proteins have been localised in the sperm plasmalemma of dog (Rigau et al. 2002), rat (Farooqui et al. 1997), human (Kokk et al. 2005) and boar (Medrano et al. 2006), highlighting their very important role in the regulation of sperm glucose and fructose metabolism.

The aim of the present study was to determine variations in the temporal localisation of the hexose- specific transporters, GLUT-3 and GLUT-5, during cooling and thawing of boar spermatozoa from Iberian pigs with respect to changes in plasma membrane integrity and motility, both of which are indicators of sperm viability and metabolic intactness.

\section{Material and Methods}

\section{Animals and sample collection}

Eight young (8-10 months old) Iberian boars of the 'Entrepelado' breed ( $n=3$, Semen Cardona, SL, Cardona, Spain) and the 'Lampiño' breed ( $n=5$, Agropecuaria de Guissona, Guissona, Spain) were used in this study. All the boars had proven fertility following Al with extended liquid semen. The experiment was carried out over a period of 3 months, with the sperm-rich fraction of the ejaculate being manually collected twice weekly, using the gloved-hand method, and analysed to ensure the quality and the homogeneity of the ejaculates. Three ejaculates were evaluated per boar (one per month), so that a total of 24 ejaculates were processed for the analysis of sperm kinematics and membrane integrity and for immunoassays. Immediately after collection, the ejaculated spermatozoa were suspended $(1: 2 ; \mathrm{v} / \mathrm{v})$ in Beltsville thawing solution (BTS; IMV, L'Aigle, France). The extended semen samples were cooled and maintained at $17{ }^{\circ} \mathrm{C}$ for shipment within $24 \mathrm{~h}$ of collection to the Division of Comparative Reproduction, Obstetrics and Udder Health, Faculty of Veterinary Medicine and Animal Sciences, Swedish University of Agricultural Sciences (SLU), Uppsala, Sweden for further processing and analyses. The experimental protocol was designed in accordance with the guidelines established by the Animal Welfare Directive of the Government of Catalonia (Spain) and the Local Ethical Committee for Experimentation with Animals, Uppsala, Sweden.

\section{Semen cryopreservation}

Immediately after the shipped semen samples were received, they were assessed for sperm motility and morphology, and only those samples with a minimum of $70 \%$ progressive motility and $80 \%$ morphologically normal spermatozoa were further processed, using a proven protocol (Eriksson \& Rodriguez-Martinez 2000). The BTS-extended semen was centrifuged in a programmable refrigerated centrifuge (Centra MP4R, IEC, Needham Heights $M N$, USA) set at $17^{\circ} \mathrm{C}$ at $800 \boldsymbol{g}$ for $10 \mathrm{~min}$. After centrifugation, the supernatant was discarded. The remaining pellets were re-extended with a lactose-egg yolk (LEY) extender $(80 \mathrm{ml}(80 \% \mathrm{v} /$ $\mathrm{v}, 310 \mathrm{mM}$ ) $\beta$-lactose $+20 \mathrm{ml}$ egg yolk), at a ratio that led to a final concentration of $1.5 \times 10^{9} \mathrm{spermatozoa} / \mathrm{ml}$. The sperm concentration was manually assessed in a Bürker haemocytometer. After thorough mixing, the semen was further cooled to $+5{ }^{\circ} \mathrm{C}$ for $2 \mathrm{~h}$ in the 
centrifuge. At this temperature, the semen was slowly mixed with a third extender consisting of $89.5 \mathrm{ml}$ LEY extender, $9 \mathrm{ml}$ glycerol and $1.5 \mathrm{ml}$ Equex STM (Nova Chemicals Sales Inc., Scituate, MA, USA), which is equivalent to Orvus Es Paste (Graham et al. 1971), at a ratio of two parts of semen to one part of extender, yielding a final concentration of glycerol of $3 \%$ and a concentration of $1 \times 10^{9}$ spermatozoa $/ \mathrm{ml}$ at $5{ }^{\circ} \mathrm{C}$. This was verified by manual counting (Bürker haemocytometer). Spermatozoa were packaged at $5{ }^{\circ} \mathrm{C}$ in a cool cabinet (IMV, L'Aigle, France) in $0.5 \mathrm{ml}$ polyvinyl chloride (PVC) plastic straws (Minitüb, Tiefenbach, Germany), which were sealed with PVC powder and placed on racks for freezing (Saravia et al. 2005). The racks were transferred to the chamber of a programmable freezer (Mini Digitcool 1400; IMV) set at $5{ }^{\circ} \mathrm{C}$. The cooling/freezing rate used was: $3^{\circ} \mathrm{C} / \mathrm{min}$ from 5 to $-5{ }^{\circ} \mathrm{C}$, $1 \mathrm{~min}$ for crystallisation and thereafter $50^{\circ} \mathrm{C} / \mathrm{min}$ from -5 to $-140^{\circ} \mathrm{C}$. The samples were then plunged into liquid $\mathrm{N}_{2}\left(-196^{\circ} \mathrm{C}\right)$ for storage (Saravia et al. 2005).

\section{Experimental design}

Sperm kinematics, plasma membrane integrity and expression of GLUT-3 and GLUT-5 were assessed at three specific stages: A) after being extended in BTS and kept chilled at $17^{\circ} \mathrm{C}$ for $\left.\sim 24 \mathrm{~h}, \mathrm{~B}\right)$ after being re-extended in extender-II and cooled to $5{ }^{\circ} \mathrm{C}$ for $2 \mathrm{~h}$ and $\mathrm{C}$ ) post-thawing. For each semen processing stage A-C), aliquots of spermatozoa were taken and examined for sperm kinematics using computer-assisted sperm analysis (CASA) and for membrane integrity using SYBR14/ethidium homodimer (EthD-1). Samples were analysed after $20 \mathrm{~min}$ of incubation at $38^{\circ} \mathrm{C}$. From each aliquot, samples were fixed by resuspension in $0.5 \%(\mathrm{w} / \mathrm{v})$ paraformaldehyde, and smears were made for immunocytochemistry of GLUT-3 and GLUT-5, for later examination in transmission and scanning electron microscopy respectively. Finally, samples were taken for SDS electrophoresis and further western blot analysis of GLUT-3 and GLUT-5.

\section{Sperm plasma membrane integrity and motility}

\section{Sperm plasma membrane integrity}

Spermatozoa were loaded with SYBR-14 and EthD-1 fluorophores (Molecular Probes Europe BV, Leiden, The Netherlands; Garner \& Johnson 1995). Semen sample $(0.5 \mathrm{ml})$ was added to $2.7 \mu \mathrm{l}$ of a $1 \mathrm{mM}$ SYBR-14 solution in dimethylsulphoxide (suspension A) and $20 \mu \mathrm{l}$ of this suspension A were mixed with $20 \mu \mathrm{l}$ solution B, containing $4 \mu \mathrm{l} \mathrm{EthD-1} \mathrm{in} 1 \mathrm{ml} \mathrm{PBS} \mathrm{(pH} \mathrm{7.2-7.4).} \mathrm{Loaded}$ spermatozoa were incubated in the dark at $34-37^{\circ} \mathrm{C}$ for $30 \mathrm{~min}$ before the preparation of wet smears for fluorescence microscope observation (Leitz Aristoplan, $600 \times)$. Spermatozoa were screened and classified into three categories: live (green), dead (red) or damaged (dual staining), and the proportion of each category was counted by two trained operators over a total of 200 spermatozoa.

\section{Sperm motility}

Twenty microlitres of each sperm sample was placed in a prewarmed $\left(38^{\circ} \mathrm{C}\right.$ ) Makler counting chamber (Sefi Medical Instruments, Haifa, Israel) and immediately analysed with a CASA instrument (SM-CMA; MTM Medical Technologies, Montreux, Switzerland) on eight predetermined optical fields around the central reticulum of the chamber. A minimum number of 200 spermatozoa were accounted for per sample. The percentage of progressively motile spermatozoa and the straight linear velocity (VSL; $\mu \mathrm{m} / \mathrm{s})$ were determined.

Sperm motility was assessed in a microscope equipped with $38{ }^{\circ} \mathrm{C}$ microscope stage and phase contrast optics (200×; Optiphot-2; Nikon, Japan), using the CASA instrument (Microptic, SL, 2002).

\section{Western blot analysis}

For western blot analysis, sperm samples were washed twice in PBS and centrifuged twice at $600 \mathrm{~g}$ for $10 \mathrm{~min}$. The pellet was then resuspended and homogenised in mixer buffer by sonication in ice-cold $10 \mathrm{mM}$ Tris-HCl buffer ('Western buffer', pH 7.4) containing $1 \%(\mathrm{w} / \mathrm{v})$ SDS; (homogenation proportion $1: 5, \mathrm{v} / \mathrm{v})+15 \mathrm{mM}$ EDTA $+150 \mathrm{mM} \mathrm{KF}+0.6 \mathrm{M}$ sacarose $+14 \mathrm{mM} \beta$-mercaptoethanol $+10.1 \mathrm{~g}$ leupeptin $+1 \mathrm{mM}$ benzamidine $+1 \mathrm{mM}$ phenyl methyl sulphonyl fluoride.

The homogenised suspension was briefly boiled and then centrifuged at $10000 \mathrm{~g}$ for $15 \mathrm{~min}$ at $4{ }^{\circ} \mathrm{C}$. Western blotting was carried out on the resultant supernatants. The total protein content of these supernatants was calculated using the Bradford method (Bradford 1976), after applying a commercial kit (Bio-Rad Laboratories).

After this procedure, which assured a homogeneous loading of protein, a total protein content of $20 \mu \mathrm{g}$ was loaded into each lane in all the experiments. The immunological analysis was based on SDS gel electrophoresis (Laemmli 1970), followed by transfer to nitrocellulose membranes (Burnette 1981). Since the freezing extender holds a significant amount of nonsperm proteins, the transfer of an equal quantity of sperm proteins to each electrophoretic lane was tested by previously staining each transferred membrane with Poinceau Red (Bio-Rad). Only those membranes holding nearly equal amounts of sperm protein per lane were subsequently subjected to western blotting. The transferred membranes were tested with the primary antibodies at a dilution ( $\mathrm{v} / \mathrm{v})$ of 1:500 for GLUT-3 and of 1:1000 (v/v) for GLUT-5 (rabbit anti-GLUT-3 (MYK antibody), an affinity-purified polyclonal antibody 
(16 amino acid synthetic peptide), which recognises the facilitative GLUT-3 in mammalian tissues, including sperm cells and rabbit anti-GLUT-5 polyclonal antibody (12 amino acid peptide), which reacts with GLUT-5 and does not cross-react with GLUT-1, -2, -3 or -4 (Chemicon Europe Ltd, Hampshire, UK)). Immunoreactive proteins were tested using a peroxidase-conjugated anti-rabbit secondary antibody (Amersham) and the reaction was developed with an ECL-Plus detection system (Amersham). The protein amount was calculated using the Bradford method (Bradford 1976), after applying a commercial kit (Bio-Rad Laboratories).

\section{Immunocytochemistry and electron microscopy}

\section{Scanning electron microscopy}

Smears were prepared by spreading sperm suspensions of each sampling point (A-C) on to superfrost polylysinecoated slides, which, immediately after being shortly airdried, were fixed in buffered paraformaldehyde $(0.5 \%)$ for $15 \mathrm{~min}$ at room temperature and further washed in PBS ( $\mathrm{pH}$ 7.2-7.4). For each slide, two or three optimal areas where spermatozoa were gathered were selected under light microscopy for immunolabelling. Nonspecific binding was blocked by incubating the smears for $1 \mathrm{~h}$ at room temperature with $2 \%$ BSA in PBS. The smears were then rinsed in PBS and incubated for $2 \mathrm{~h}$ at room temperature with the same western blot analysis antibodies GLUT-3 and GLUT-5, at a dilution of 1:500 $(\mathrm{v} / \mathrm{v})$ in PBS for both cases. The spermatozoa were then washed in PBS and incubated with goat anti-rabbit lgG$15 \mathrm{~nm}$ gold (1:25; Auroprobe; Amersham) for $1 \mathrm{~h} 50 \mathrm{~min}$ at room temperature. After this, the samples were washed in PBS and distilled water and then subjected to silver enhancement (IntenSE silver enhancement system for microscopy) for $10 \mathrm{~min}$ and air-dried for $24 \mathrm{~h}$ in the dark. The smears were coated with platinum/palladium (High Resolution Sputter Coater; Agar Scientific, Accessories for Microscopy, Essex, England) for $10 \mathrm{~min}$ and selected regions of the glass were cut and mounted on to stubs for observation under an electron scanning microscope (Jeol SEM 1230 Electron Microscope, at $20 \mathrm{kV}$ of filament intensity).

\section{Transmission electron microscopy}

Spermatozoa suspension fixed in $0.5 \%(\mathrm{w} / \mathrm{v})$ paraformaldehyde in $0.1 \mathrm{M}$ phosphate (Sorensen's) buffer $(\mathrm{pH}$ 7.3) for $1 \mathrm{~h}$ at $4{ }^{\circ} \mathrm{C}$ was centrifuged at $800 \mathrm{~g}$ for $10 \mathrm{~min}$. The resulting pellet was washed thrice in PBS and preembedded in $2 \%(\mathrm{w} / \mathrm{v})$ Agar in PBS to obtain working blocks, which were conventionally dehydrated in graded alcohol solutions $\left(70^{\circ}, 96^{\circ}\right.$ and absolute alcohol, $15 \mathrm{~min}$ per step). The dehydrated samples were progressively embedded at $4{ }^{\circ} \mathrm{C}$ in LR-White acrylic resin (Acrylic Resin; TAAB Essentials for Microscopy, Berkshire, England), transferred to capsules (1 block/capsule) and polymerised for $24 \mathrm{~h}$ at $50{ }^{\circ} \mathrm{C}$. Semithin $(1-3 \mu \mathrm{m})$ and ultrathin $(60-$ $80 \mathrm{~nm}$ ) sections were obtained, and the latter mounted on 300 mesh nickel grids (Amersham) for immunocytochemical labelling. Non-specific binding was blocked by incubating the sections for $1 \mathrm{~h}$ at room temperature with $2 \%$ normal goat serum in $1 \%$ BSA/PBS. The sections were then washed in PBS and incubated with a 1:500 dilution of GLUT-3 or GLUT-5 antibodies in $0.1 \%$ BSA/PBS for $2 \mathrm{~h}$ at room temperature. The grids were coated with $1 \%(\mathrm{w} / \mathrm{v})$ BSA in PBS (buffered BSA) for $20 \mathrm{~min}$, followed by incubation with either GLUT-3 or GLUT-5 antibodies $(1: 500, \mathrm{v} / \mathrm{v}$ in PBS) for $2 \mathrm{~h}$ at room temperature. Preimmune rabbit serum and the specific antibody, preabsorbed with saturating concentrations of the corresponding peptide, were used in the primary incubation step as negative stained controls. After extensive washing in a buffer composed of $0.1 \%(\mathrm{w} / \mathrm{v}) \mathrm{BSA}, 0.15 \mathrm{M} \mathrm{NaCl}$ and $0.01 \mathrm{M}$ phosphate buffer (PBB buffer; $\mathrm{pH} 7.4$ ), the sections were incubated with A-protein-gold (AuroProbe EM G $15 \mathrm{~nm}$; Amersham Corporation) at a dilution of $1: 100(\mathrm{w} / \mathrm{v})$ in PBB buffer for $1 \mathrm{~h}$ at room temperature. After being washed thrice in $0.15 \mathrm{M} \mathrm{NaCl}$ for $3 \mathrm{~min}$, the cells were finally counterstained with $2 \%(\mathrm{w} / \mathrm{v})$ uranyl acetate in distilled water for $30 \mathrm{~min}$ and $3 \%(\mathrm{w} / \mathrm{v})$ lead citrate in distilled water for $10 \mathrm{~min}$ (Reynolds 1963).

\section{Statistical analysis}

For the evaluation of sperm integrity and motility, statistical comparisons of samples were performed by multi-ANOVA (MANOVA). Student's $t$-test was used to compare least square means, and a general linear model was included to assess the differences among the different classes. The level of significance was set at $P<0.05$.

\section{Results \\ Sperm functional parameters}

\section{Sperm plasma membrane integrity}

The percentage of live spermatozoa after thawing (step C) was significantly lower in the Entrepelado breed $(P<0.05)$, but not in the Lampiño breed. No such difference between the breeds was noted for steps $A$ and B (Table 1).

\section{Sperm motility}

Percentages of both motility and VSL showed no significant differences during cryopreservation between the Entrepelado and Lampiño breeds. Comparisons among the three stages of the cryopreservation process showed significant lower values $(P<0.05)$ of motility in post-thawed semen (step C) in both varieties, but VSL remained similar (Table 2). Moreover, percentages of motile spermatozoa were similar between 0 - and 30-min post-thawing (step C), 
Table 1 Membrane integrity in three stages of cryopreservation process (A, B and C). Results are expressed as mean \pm s.D. of 24 separate experiments.

\begin{tabular}{|c|c|c|c|c|c|c|}
\hline & \multicolumn{3}{|c|}{ Entrepelado boars } & \multicolumn{3}{|c|}{ Lampiño boars } \\
\hline & $17^{\circ} \mathrm{C}(\mathrm{A})$ & $5{ }^{\circ} \mathrm{C}(\mathrm{B})$ & Post-thawing $(\mathrm{C})$ & $17^{\circ} \mathrm{C}(\mathrm{A})$ & $5{ }^{\circ} \mathrm{C}(\mathrm{B})$ & Post-thawing $(\mathrm{C})$ \\
\hline Live (\%) & $65.05 \pm 8.10$ & $69.75 \pm 7.44$ & $44.76^{*} \pm 12.05$ & $62.72 \pm 11.98$ & $64.44 \pm 9.76$ & $51.37 \pm 7.45$ \\
\hline Dead (\%) & $20.93 \pm 6.81$ & $30.70 \pm 9.31$ & $46.22 * \pm 11.29$ & $28.69 \pm 7.49$ & $28.25 \pm 6.49$ & $40.06 \pm 6.23$ \\
\hline Damaged (\%) & $7.07 \pm 0.24$ & $4.32 \pm 0.06$ & $9.02 * \pm 0.71$ & $6.87 \pm 0.77$ & $8.56 \pm 0.48$ & $8.56 \pm 1.12$ \\
\hline
\end{tabular}

*Values statistically different from refrigerated semen $(P<0.05)$.

but VSL was significantly lower $(P<0.05)$ after more than 30-min post-thawing in both varieties (Table 3 ).

\section{Immunocytochemistry of GLUT-3 and GLUT-5}

The analyses of the SEM and TEM immunolabelling clearly showed that the boar spermatozoa expressed the hexose transporters, GLUT-3 and GLUT-5, in both the outer and inner plasmalemma. The expression of the hexose transporter isoform GLUT-3, however, showed a different distribution, in terms of both location and concentration among spermatozoa as well as during the various steps of the freezing-thawing protocol used (steps A-C; Figs 1 and 2).

Strong GLUT-3 immunoreactivity was observed in the sperm acrosome membrane of $17^{\circ} \mathrm{C}$-semen (step A), especially in the anterior half of the head clearly delimited by the equatorial segment. The post-acrosomal region showed moderate immunoreactivity with the anti-GLUT-3, while the connecting piece, the midpiece and the principal piece of the sperm tail presented weak immunoreactivity with this antibody (Fig. 1). This pattern of reactivity was maintained in these cells at $5{ }^{\circ} \mathrm{C}$ (step B) after adding glycerol during the cryopreservation process, but, post-thaw (step C), the immunolabelling became less clear in terms of both intensity and distribution (Fig. 1).

The immunolabelling of the hexose isoform GLUT-5 in $17^{\circ} \mathrm{C}$-spermatozoa (step A) was mainly located in the apical and principal segments of the acrosomal region, with a moderate labelling in the post-acrosomal region (Fig. 2). However, strong immunoreactivity was also detected along the connecting piece, the midpiece and the principal piece of the sperm tail (Fig. 2). By contrast with what was seen for GLUT-3, the immunolabelling pattern was maintained at $5{ }^{\circ} \mathrm{C}$ (step B) and post-thaw (step C; Fig. 2).

\section{Western blot analysis of GLUT-3 and GLUT-5 expression}

The presence of hexose transporters, GLUT-3 and GLUT5, was confirmed by western blotting of the boar spermatozoa using the same specific antibodies for each hexose transporter. For GLUT-3 and GLUT-5, results showed the presence of specific bands of about $50 \mathrm{kDa}$, which were maintained during cooling (steps $\mathrm{A}$ and $\mathrm{B}$ ) and post-thaw (step C). The band for GLUT-3 corresponded well to that already described in boar spermatozoa (Medrano et al. 2006). However, the intensity of this specific GLUT-3 band in supernatants from sperm extracts decreased, in almost all cases, during the cooling and thawing steps $(\mathrm{A}-\mathrm{C})$ when compared with equivalent fresh sperm samples (Fig. 3), while that of GLUT-5 increased during steps $\mathrm{A}-\mathrm{C}$ when compared with equivalent freshly collected spermatozoa (Fig. 3).

\section{Discussion}

Cryopreservation, as per the protocol used in the present study, caused dramatic deterioration in sperm viability in Iberian boars, with very low post-thaw survival. Cooling to $5^{\circ} \mathrm{C}$ does not seem to be the problem, since no significant changes were detected at either 17 or $5{ }^{\circ} \mathrm{C}$. This suggests that an understanding of the physiological status achieved by boars at temperatures below $5{ }^{\circ} \mathrm{C}$ would be crucial to explain boar sperm survival during the cooling-freezing process. These results agree with those of Maldjian et al. (2005), who pointed out that the temperature which produces the greatest effect during cryopreservation is the cooling-freezing step below $5{ }^{\circ} \mathrm{C}$.

In our study, the sperm motility percentages obtained are lower than the standard values for post-thawed semen in non-lberian boars (45-50\%; Bwanga et al. 1990). However, no real data exist for this parameter in Iberian boars and differences in experimental design, package systems, breeds or individual male responses to

Table 2 Total sperm motility and straight linear velocity (VSL) in three stages of cryopreservation process (A-C). Results are expressed as mean \pm s.D. of 24 separate experiments.

\begin{tabular}{|c|c|c|c|c|}
\hline & \multicolumn{2}{|c|}{ Entrepelado boars } & \multicolumn{2}{|c|}{ Lampiño boars } \\
\hline & Motility (\%) & VSL $(\mu \mathrm{m} / \mathrm{s})$ & Motility (\%) & $\operatorname{VSL}(\mu \mathrm{m} / \mathrm{s})$ \\
\hline Refrigerated semen $\left(17^{\circ} \mathrm{C} ; \mathrm{A}\right)$ & $79.9 \pm 11.7$ & $62.6 \pm 16.1$ & $73.3 \pm 39.6$ & $47.3 \pm 21.6^{+}$ \\
\hline Semen at $5{ }^{\circ} \mathrm{C}(\mathrm{B})$ & $80.1 \pm 9.8$ & $79.4 \pm 14.5$ & $77.0 \pm 13.9$ & $82.5 \pm 18.5$ \\
\hline Post-thawed semen (C) & $37.6 \pm 13.3^{*^{+}}$ & $79.9 \pm 10.9$ & $35.6 \pm 9.0^{\dagger}$ & $65.0 \pm 8.3^{\dagger}$ \\
\hline
\end{tabular}

*Values statistically different from refrigerated semen $(P<0.05)$. ${ }^{+}$Values statistically different from semen at $5{ }^{\circ} \mathrm{C}(P<0.05)$. 
Table 3 Total sperm motility and straight linear velocity (VSL) post-thawing (C). Results are expressed as mean \pm s.D. for 24 separate experiments.

\begin{tabular}{|c|c|c|c|c|}
\hline \multirow[b]{2}{*}{ Post-thawing (time after) } & \multicolumn{2}{|c|}{ Entrepelado boars } & \multicolumn{2}{|c|}{ Lampiño boars $(\mu \mathrm{m} / \mathrm{s})$} \\
\hline & Motility (\%) & $\operatorname{VSL}(\mu \mathrm{m} / \mathrm{s})$ & Motility (\%) & VSL \\
\hline $\begin{array}{l}0 \text { min } \\
30 \min \end{array}$ & $\begin{array}{l}37.6 \pm 13.3 \\
35.6 \pm 9.0\end{array}$ & $\begin{array}{l}79.9 \pm 10.9 \\
65.0 \pm 8.3\end{array}$ & $\begin{array}{l}35.6 \pm 16.3 \\
36.3 \pm 9.4\end{array}$ & $\begin{array}{l}61.0 \pm 11.0^{*} \\
52.2 \pm 7.3^{*}\end{array}$ \\
\hline
\end{tabular}

*Values statistically different between 0 - and 30-min post-thawing $(C ; P<0.05)$.

cryopreservation must also obviously be taken into account.

Our results showed a VSL increase at $5{ }^{\circ} \mathrm{C}$, but values between refrigerated and post-thawed semen remain similar. Other authors have reported a slight increase in sperm non-progressive hyperactivity movement at $5{ }^{\circ} \mathrm{C}$, although the proportion differs among boars (Cremades et al. 2005). The VSL represents the progressive linear motility in a sperm sample, with the result that many kinds of movement are included in the total sperm motility category.

Our study showed that the sperm membrane integrity in Iberian boars was severely affected post-thaw, and that at $5{ }^{\circ} \mathrm{C}$, the most important effect is at acrosomal level. Several other authors have also observed an increase of 50-60\% altered acrosomes after thawing (Bwanga et al. 1990, Fiser \& Fairfull 1990, Hofmo \& Almlid 1991, Verheyen et al. 1993).

One of the major findings in this study, besides the presence of both GLUT-3 and GLUT-5 on the outer and inner plasma membrane of boar spermatozoa, is the fact that the protein distribution changed during the process, particularly for GLUT-3, whose labelling decreased dramatically post-thaw. These concomitant changes in the membrane would result in a reduction in its ability to use energetic nutrients (De Leeuw et al. 1990, Watson 1995), resulting in compromised motility and/or membrane integrity.

Our results indicate that boar spermatozoa express the family members of the facilitative hexose transporters, GLUT-3 and GLUT-5. All these proteins are localised on specific cellular compartments at the level of the sperm head and tail, and their distribution is characteristic. This is logical, since the uptake of essential sugars, such as glucose and fructose, to maintain energy metabolism is mediated for both transporters. Thus, GLUT-3 is a very effective glucose transporter, as has been already reported not only for boar spermatozoa (Medrano et al. 2006), but also for the sperm membrane of other mammals, such as rat (Farooqui et al. 1997), bull (Angulo et al. 1998), dog (Rigau et al. 2002) and human (Haber et al. 1993). On the other hand, GLUT-5 is a fructose-specific transporter, which has been reported in dog (Rigau et al. 2002), bull (Angulo et al. 1998) and human (Burant et al. 1992) spermatozoa. Our results show that the GLUT-3 molecules in the head of boar spermatozoa are located only at the acrosome region in $17^{\circ} \mathrm{C}$-semen. This location is maintained during further cooling and after thawing. The expression along the midpiece and the principal piece of the tail was moderate in intensity in $17^{\circ} \mathrm{C}$-semen and $5{ }^{\circ} \mathrm{C}$ semen, and poor post-thaw. This carrier is essential for the entry of substrates (in this case glucose) into the spermatozoon, and the uneven distribution in the different sperm domains might link its presence to different metabolic pathways in the spermatozoon, pathways that are not necessarily linked to sperm motility but rather to housekeeping metabolism (membrane activity, etc). This would account for it being located at the highest intensity in the rostral region. Fraser \& Quinn (1981) suggested a direct relationship between the expression of GLUT-3 in the acrosome region and the accommodation to a medium with low levels of glucose. Regarding this point, it has been said that boar spermatozoa show a very different affinity to utilise separate monosaccharides, such as glucose, fructose, sorbitol and mannose, and one of the key points in regulating this is the presence and location of separate hexose transporters such as GLUT-3 (Ballester et al. 2004, Medrano et al. 2006). This implies that the exact location of a specific hexose transporter would be the first regulatory step in the utilisation of a particular carbohydrate to obtain energy. During cryopreservation, the lipids of the sperm membrane are modified in terms of relocation, dispersion and exit, all provoking different alterations in sperm morphology and, in particular, function. Obviously, the changes in the fluidity of the lipid bilayer are accompanied by relocation of the structural proteins of the membrane, including the changes in the localisation and distribution of hexose transporters during cryopreservation. This hypothesis is supported by our results, which show that post-thawed spermatozoa lost the characteristic display of immunolabelling for GLUT-3, perhaps as a result of the loss of these carriers from the membrane. This phenomenon can be related to the decrease of GLUT-3 in the sperm supernatants during cooling, freezing and thawing. Obviously, maintaining the structure of the plasma membrane is perhaps the most challenging task when preserving boar spermatozoa, since alterations to the plasmalemma conspire against the integrity of the cell, its survival and, even for the survivors, the ability to maintain metabolism and fertilising capacity. GLUT-3 has recently been co-localised at various stages of differentiation in lipid membrane domains of spermatogenic cells also harbouring caveolin-1 (Rauch et al. 

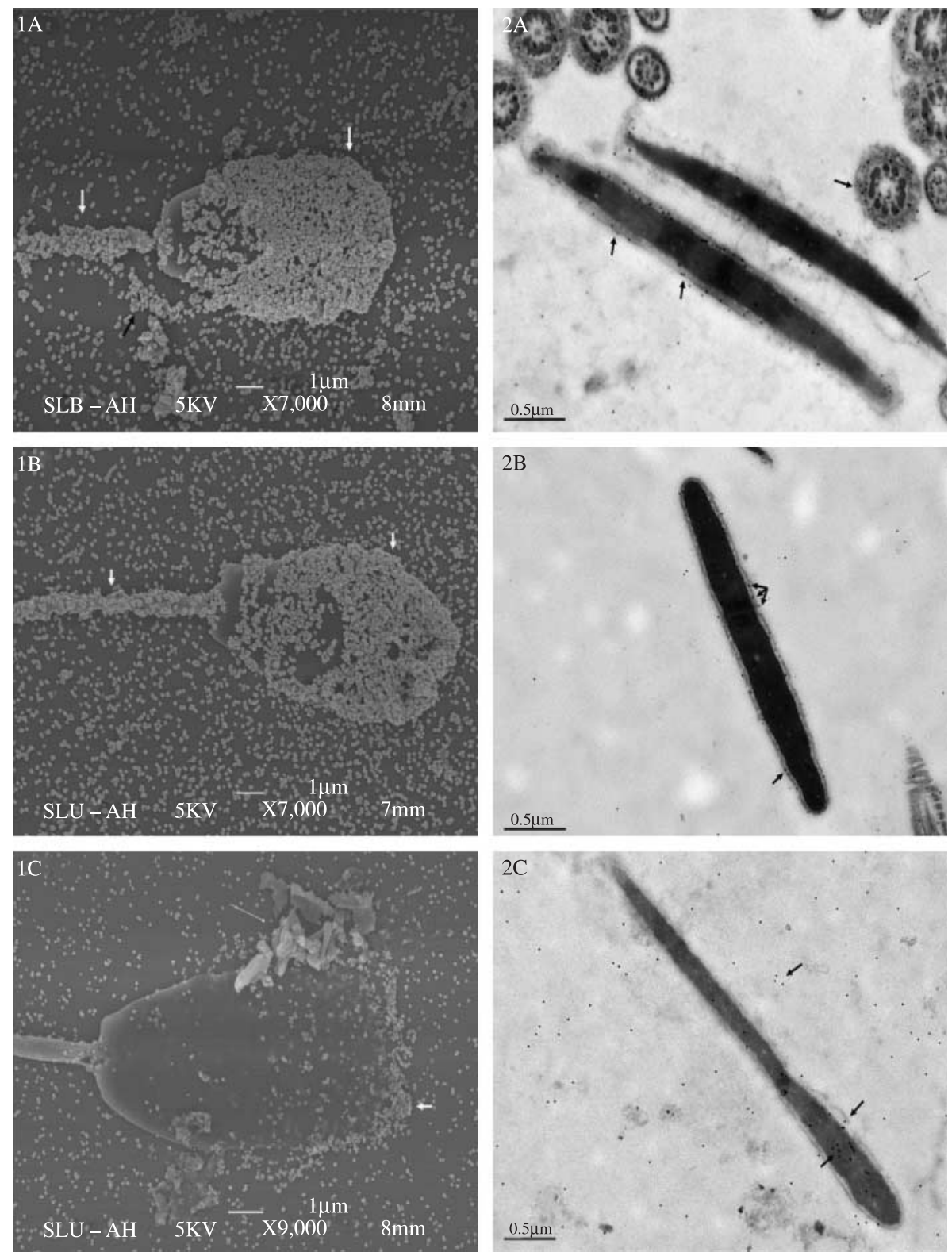

Figure $1 \mathrm{Immunolocalisation}$ of the hexose transporter, GLUT-3, in Iberian boar spermatozoa. Spermatozoa were spread onto coated slides (1) or embedded and cut in ultrathin sections (2) and probed with the GLUT-3 antibody followed by incubation with a secondary antibody coupled to colloidal gold and counterstained with silver enhancement. Images came from three steps of the freezingthawing protocol. A: in refrigerated semen at $17{ }^{\circ} \mathrm{C}$; B: at $5{ }^{\circ} \mathrm{C}$, after addition of glycerol; C: post-thaw.
2006). This suggests that the lipid disorder linked to cooling/freezing/thawing would lead to a concomitant alteration in the caveolar structure of the sperm membrane, which, in turn, would greatly alter the location and the presence of caveolae-linked membrane proteins such as GLUT-3. The maintenance of the GLUT3 location in $5{ }^{\circ} \mathrm{C}$-spermatozoa suggests that the problem is not present there, but it appears during either the subzero handling or the thawing process.

The expression of GLUT-5 followed a different pattern, being centred in the post-acrosomal region and along the midpiece and the principal piece of the tail and undergoing no changes in location, distribution or intensity of immunolabelling, despite the spermatozoa being damaged by the cryopreservation process. This distribution in boar spermatozoa differs from that seen in human spermatozoa, where GLUT-5 was only moderately expressed in the post-acrosomal region but strongly expressed along the tail (Angulo et al. 1998). In mammals, fructose is mainly internalised from the seminal plasma by the GLUT-5 sperm membrane carrier, directly affecting the glycolytic activity of the midpiece of the tail and, consequently, sperm motility (Grootegoed \& Den Boer 1990). Fructose is produced and excreted by seminal vesicles and, in boars, represents an important substrate to store for special situations (Setchell et al. 1994, Garner \& Hafez 1996, Catt et al. 1997, Jones \& Bubb 2000, Jones \& Connor 2000, Sancho et al. 2004, 2006), although the affinity for and the rate of use of fructose in pig spermatozoa are lower than that of 

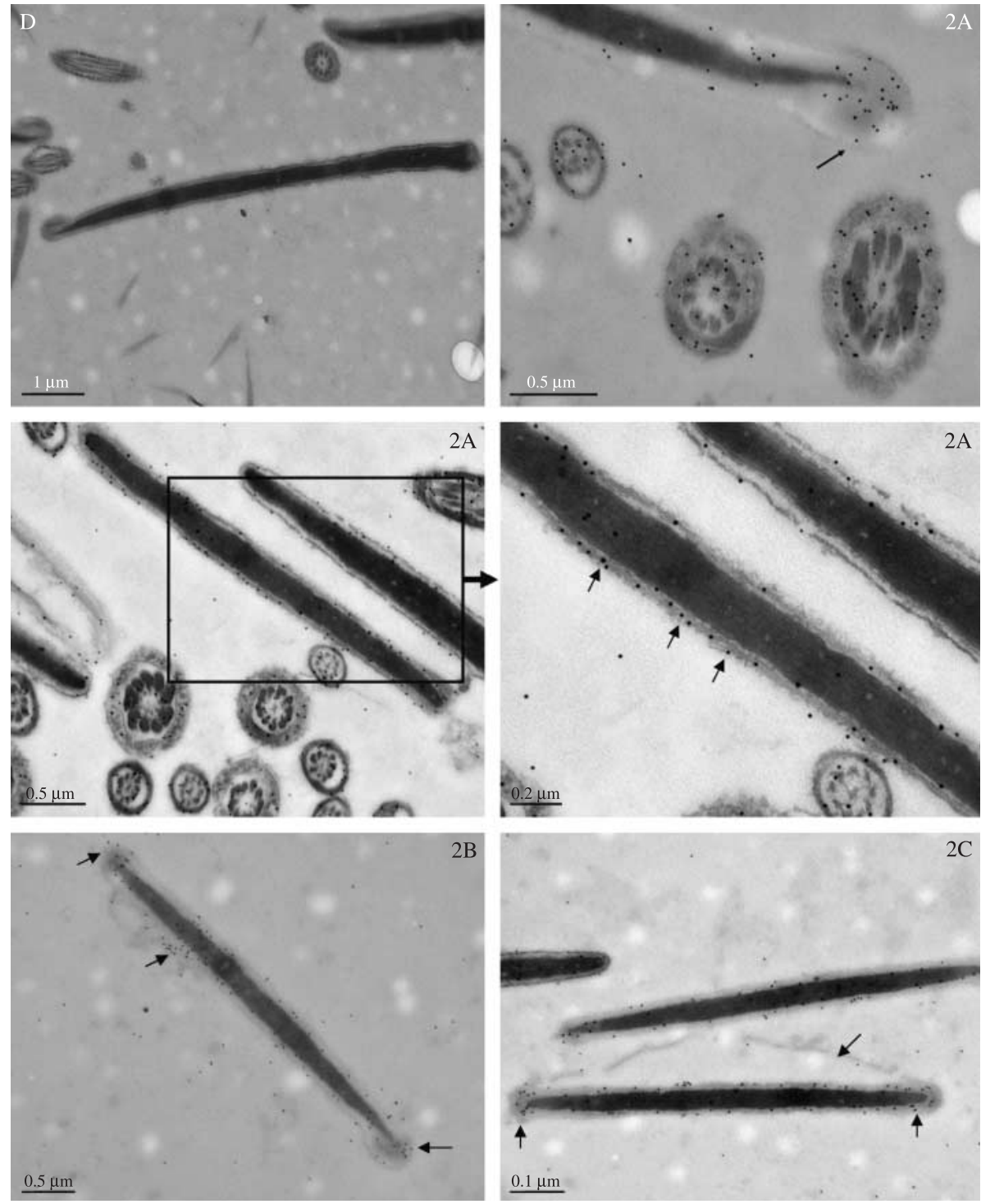

Figure $2 \mathrm{Immunolocalisation}$ of the hexose transporter, GLUT-5, in Iberian boar spermatozoa. Spermatozoa were spread onto coated slides (1) or embedded and cut in ultrathin sections (2) and probed with the GLUT-5 antibody followed by incubation with a secondary antibody coupled to colloidal gold and counterstained with silver enhancement. Images came from three steps of the freezingthawing protocol. A: in refrigerated semen at $17^{\circ} \mathrm{C}$; B: at $5{ }^{\circ} \mathrm{C}$, after addition of glycerol; C: post-thaw; D: control for the technique. glucose (Jones \& Connor 2000, Medrano et al. 2006). These differences in the affinity of both glucose and fructose might be due to several factors, one of which is the different affinity that the total hexokinase activity of boar sperm shows for each of them (Medrano et al. 2006). However, it is certain that the first step marking the different utilisation of glucose and fructose would be related to their specific transporters. The differences observed in the specific location of GLUT-3 and GLUT-5 could be related to these different uses. Our results suggest that both GLUT-3 and GLUT-5 are differently associated with other sperm cell structures. Thus, whereas cooling/freezing caused a decrease in the presence of GLUT-3 in the soluble membrane-linked sperm fraction, the same process caused an increase in the presence of GLUT-5. This difference could be related to GLUT-5 being associated with non-soluble sperm structures, such as dense fibres or mitochondria, and thus primarily linked to motility. There are various possible pathways for the use of these energetic substrates, for example glycolytic versus aerobic pathways, to maintain both the housekeeping needs and the active physiology of the cell. The flagellar function, related to sperm motility and the ATP consuming process, is today a changing concept, since flagellar movement is related to the local ability to produce ATP anaerobically by glycolysis, while the aerobic (e.g. mitochondrial) producing ATP is used for housekeeping metabolism in the midpiece and head domains (Miki et al. 2004, Silva \& Gadella 2006).

The overall structural alteration caused by the cooling/freezing process would, in turn, induce an alteration in the association of GLUT-5 with these non-soluble structures, and the result would be an increased presence of GLUT-5 in the sperm soluble fraction. On the other hand, GLUT-3, which seems to be mainly linked to the cell 
A

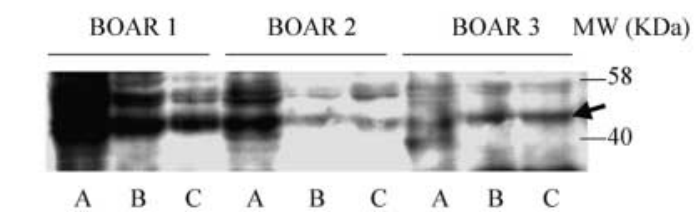

B

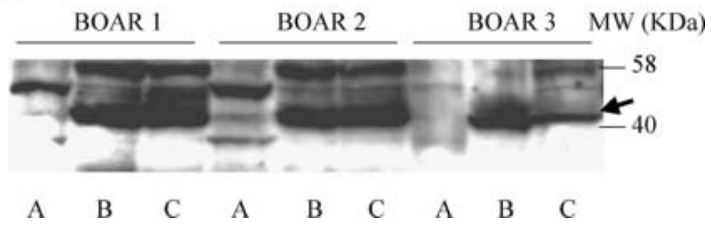

Figure 3 Specific expressions of hexose transporters, GLUT-3 and GLUT-5, in supernatants obtained from Iberian boar sperm extracts. The Figure shows a representative image of western blot analysis for GLUT-3 (a) and GLUT-5 (b) in supernatants from Iberian boar sperm extracts subjected to separate steps of cryopreservation (A-C) run in three experiments (BOAR 1, BOAR 2 and BOAR 3). The obtainment of supernatants from boar sperm extracts has been described in the Materials and Methods section. A: extracts from fresh samples before freezing/thawing. B: extracts from samples after the cooling phase included into the freezing/thawing process (final of the step 3 of the freezing/thawing protocol; see Materials and Methods). C: extracts from thawed samples (final of the step 8 of the freezing/thawing protocol; see Materials and Methods). MW: molecular weight markers. Arrows indicate locations of the specific bands of both GLUT-3 and GLUT-5 (number of replicates $=6$ ).

membrane, will simply be lost after cooling/freezing/thawing, explaining the clearly visible decrease in the presence of GLUT-3 in the supernatants of boar sperm extracts post-thaw. We can only speculate as to how these differences in both localisation and association with other sperm structures modulate the activity of hexose transporters. In any case, the cooling/freezing-associated alterations would induce changes in the ability of boar sperm to manage their energy levels, thus altering overall sperm function after thawing.

In conclusion, the present study confirms the reduction of sperm quality in cryopreserved Iberian semen and reveals that temperatures under $5{ }^{\circ} \mathrm{C}$ seem to be a major factor in explaining the failure of sperm to survive the freezing-thawing process. In addition, the effects of cooling-freezing temperatures on the sperm boar membranes, the specific liability of this sperm cell and a wide variation among individual males might contribute to the poor successful response to the cryopreservation of this gamete.

\section{Acknowledgements}

This research was supported by the Spanish Government's Plan Nacional I+D+I projects AGL2004-04756-002-01 GAN and RZ03-029 and by the Autonomous Government of Catalonia's Direcció General de Recerca project 2005SGR-0025 and was made possible by a mobility grant from the University of
Girona. Our special thanks to Åsa Jansson, Karin-Selin Wretling and Anika Rikberg, Division of Comparative Reproduction, Obstetrics and Udder Health, SLU, Sweden for their valuable technical assistance in electron microscopy preparation and semen evaluation. We also thank Semen Cardona, S L and Agropecuaria de Guissona, Spain for providing the animals. The authors declare that there is no conflict of interest that would prejudice the impartiality of this scientific work.

\section{References}

Angulo C, Rauch MC, Droppelmann A, Reyes AM, Slebe JC, DelgadoLópez F, Guaiquil VH, Vera JC \& Concha II 1998 Hexose transporter expression and function in mammalian spermatozoa: cellular location and transport of hexoses and vitamin C. Journal of Cellular Biochemistry 71 189-203.

Ballester J, Muñoz MC, Domínguez J, Rigau T, Guinovart JJ \& Rodriguez-Gil JE 2004 Insulin-dependent diabetes affects testicular function by FSH- and LH linked mechanisms. Journal of Andrology 25 706-719.

Bathgate R, Maxwell WM \& Evans G 2006 Studies on the effect of supplementing boar semen cryopreservation media with different avian egg yolk types on in vitro post-thaw sperm quality. Reproduction in Domestic Animals 41 68-73.

Bradford MM 1976 A rapid and sensitive method for the quantitation of microgram quantities of protein utilizing the principle of protein-dye binding. Analytical Biochemistry 72 248-254.

Breininger E, Beorlegui NB, O'Flaherty CM \& Beconi MT 2005 Alphatocopherol improves biochemical and dynamic parameters in cryopreserved boar semen. Theriogenology 63 2126-2135.

Burant CF, Takeda J, Brot-Laroche E, Bell GI \& Davidson NO 1992 Fructose transporter in human spermatozoa and small intestine is Glut 5. Journal of Biological Chemistry 267 14523-14526.

Burnette WM 1981 Western blotting: electrophoretic transfer of proteins from sodium dodecyl sulfate-polyacrylamide gels to unmodified nitrocellulose and radiographic detection with antibody and radioiodinated proteins. Analytical Biochemistry 112 195-203.

Bwanga CO 1991 Cryopreservation of boar semen I: a literature review. Acta Veterinaria Scandinavica 32 431-453.

Bwanga CO, de Bragança MM, Einarsson S \& Rodriguez-Martinez H 1990 Cryopreservation of boar semen in mini- and maxi-straws. Zentralblatt Für Veterinärmedizin Reihe A 37 651-658.

Carvajal G, Cuello C, Ruiz M, Vazquez JM, Martinez EA \& Roca J 2004 Effects of centrifugation before freezing on boar sperm cryosurvival. Journal of Andrology 25 389-396.

Catt SL, Sakkar D, Bizzarro D, Bianchi PG, Maxwell WM \& Evans G 1997 Hoechst staining and exposure to UV laser during flow cytometric sorting does not affect the frequency of detected endogenous DNA nicks in abnormal and normal human spermatozoa. Molecular Human Reproduction 3 821-825.

Cerolini S, Maldjian A, Pizzi F \& Gliozzi TM 2001 Changes in sperm quality and lipid composition during cryopreservation of boar semen. Reproduction 121 395-401.

Colenbrander B, Gadella BM \& Stout TA 2003 The predictive value of semen analysis in the evaluation of stallion fertility. Reproduction in Domestic Animals 38 305-311.

Cremades T, Roca J, Rodriguez-Martinez H, Abaigar T, Vazquez JM \& Martinez EA 2005 Kinematic changes during the cryopreservation of boar spermatozoa. Journal of Andrology 26 610-618.

Curry WJ, Norlen P, Barkatullah SC, Johnston CF, Hakanson R \& Hutton JC 2000 Chromogranin A and its derived peptides in the rat and porcine gastro-entero-pancreatic system. Expression, localization, and characterization. Advances in Experimental Medicine and Biology 482 205-213. 
Eriksson BM \& Rodriguez-Martinez H 2000 Effect of freezing and thawing rates on the post-thaw viability of boar spermatozoa frozen in flat-packs and maxi-straws. Animal Reproduction Science 63 205-220.

Farooqui SM, Fakhri AI-B, O'Donnell JM \& Stout R 1997 Degenerative changes in spermatogonia are associated with loss of glucose transporter (Glut-3) in abdominal testis of surgically induced unilateral cryptorchidism in rats. Biochemical and Biophysical Research Communications 236 407-412.

Fiser PS \& Fairfull RW 1990 Combined effect of glycerol concentrations and cooling velocity on motility and acrosomal integrity of boar spermatozoa frozen in $0.5 \mathrm{ml}$ straws. Molecular Reproduction and Development 25 123-129.

Fraser LR \& Quinn PJ 1981 A glycolytic product is obligatory for initiation of the sperm acrosome reaction and whiplash motility required for fertilization in the mouse. Journal of Reproduction and Fertility $6125-35$.

Garner DL \& Hafez ESE 1996 Espermatozoides y plasma seminal. In Reproducción e Inseminación Artificial en Animales, pp 158-179. Ed. ESE Hafez. Interamericana: McGraw-Hill.

Garner DL \& Johnson LA 1995 Viability assessment of mammalian using SYBR-14 and propidium iodide. Biology of Reproduction 53 276-284.

Graham EF, Schmehl ML, Brown KI, Crabo BG \& Ertel G 1971 Some chemical studies of the female reproductive tract and seminal plasma of the male turkey and their relationship to fertility. Poultry Science 50 1170-1181.

Grootegoed JP \& Den Boer PJ 1990 Energy metabolism of spermatids: a review. In Scientific Basis for Fertility Regulation. Cellular and Molecular Events in Spermiogenesis, Eds DW Hamilton \& GMH Waites. Cambridge: Cambridge University Press.

Guthrie HD \& Welch GR 2005 Effects of hypothermic liquid storage and cryopreservation on basal and induced plasma membrane phospholipid disorder and acrosome exocytosis in boar spermatozoa. Reproduction, Fertility, and Development 17 467-477.

Haber RS, Weinstein SP, O'Boyle E \& Morgello S 1993 Tissue distribution of the human Glut-3 glucose transporter. Endocrinology 132 2538-2543.

He L, Bailey JL \& Buhr MM 2001 Incorporating lipids into boar semen decreases chilling sensitivity but not capacitation potential. Biology of Reproduction 64 69-79.

Hofmo PO \& Almlid T 1991 Recent development in freezing of boar semen with special emphasis on cryoprotectants. Proceedings of the Second Interrnational Conference on Boar Semen Preservation, pp 11-122. Beltsville, MD, USA.

Holt WV \& North RD 1984 Partially irreversible cold-induced lipid phase transitions in mammalian sperm plasma membrane domains: freeze-fracture study. Journal of Experimental Zoology 230 473-483.

Johnson LA, Weitze KF, Fiser P \& Maxwell WMC 2000 Storage of boar semen. Animal Reproduction Science 62 143-172.

Jones AR \& Bubb WA 2000 Substrates for endogenous metabolism by mature boar spermatozoa. Journal of Reproduction and Fertility 119 129-135.

Jones AR \& Connor DE 2000 Fructose metabolism by mature boar spermatozoa. Reproduction, Fertility, and Development 12 355-359.

Kokk K, Verajankorva E, Laato M, Wu XK, Tapfer H \& Pollanen P 2005 Expression of insulin receptor substrates 1-3, glucose transporters Glut-1-4, signal regulatory protein 1 alpha, phosphatidylinositol 3-kinase and protein kinase $B$ at the protein level in the human testis. Anatomical Science International 80 91-96.

Laemmli UK 1970 Cleavage of structural proteins during the assembly of the head of bacteriophage T4. Nature 227 680-685.

De Leeuw FE, Chen HC, Colenbrander B \& Verkleij AJ 1990 Coldinduced ultrastructural changes in bull and boar sperm plasma membranes. Cryobiology 27 171-183.

Maldjian A, Pizzi F, Gliozzi T, Cerolini S, Penny P \& Noble R 2005 Changes in sperm quality and lipid composition during cryopreservation of boar semen. Theriogenology 63 411-421.
Maxwell WMC \& Johnson LA 1997 Membrane status of boar spermatozoa after cooling or cryopreservation. Theriogenology $\mathbf{4 8}$ 209-219.

Mazur P 1963 Kinetics of water loss from cells at subzero temperatures and the likelihood of intracellular freezing. Journal of General Physiology 47 347-369.

Medrano A, Garcia-Gil N, Ramió L, Rivera MM, Fernández-Novell JM, Ramírez A, Peña A, Briz MD, Pinart E, Concha II, Bonet S, Rigau T \& Rodríguez-Gil JE 2006 Hexose-specificity of hexokinase and ADPdependence of pyruvate kinase play important roles in the control of monosaccharide utilization in freshly diluted boar spermatozoa. Molecular Reproduction and Development 73 1179-1194.

Miki K, Qu W, Goulding EH, Willis WD, Bunch DO, Strader LF, Perreault SD, Eddy EM \& O'Brien DA 2004 Glyceraldehyde 3 -phosphate dehydrogenase-S, a specific enzyme, is required for sperm motility and male fertility. PNAS 101 16501-16506.

Ollero M, Perez-Pe R, Muino-Blanco T \& Cebrian-Perez JA 1998 Improvement of ram sperm cryopreservation protocols assessed by sperm quality parameters and heterogeneity analysis. Cryobiology 37 1-12.

Parks JE \& Graham JK 1992 Effects of cryopreservation procedures on sperm membranes. Theriogenology 38 209-222.

Parks JE \& Lynch DV 1992 Lipid composition and thermotropic phase behaviour of boar, bull, stallion, and rooster sperm membranes. Cryobiology 29 255-256.

Peña FJ, Saravia F, Núñez-Martínez I, Johannisson A, Wallgren M \& Rodriguez-Martinez H 2005 Do different portions of the boar ejaculate vary in their ability to sustain cryopreservation? Animal Reproduction Science 93 101-113.

Pettit MJ \& Buhr MM 1998 Extender components and surfactants affect boar sperm function and membrane behaviour during cryopreservation. Journal of Andrology 19 736-746.

Pursel VG, Johnson LA \& Schulman LL 1973 Effect of dilution, seminal plasma and incubation period on cold shock susceptibility of boar spermatozoa. Journal of Animal Science 37 528-531.

Rauch MC, Ocampo ME, Bohle J, Amthauer R, Yánez AJ, Rodríguez-Gil JE, Slebe JC, Reyes JG \& Concha II 2006 Hexose transporters Glut- 1 and Glut- 3 are colocalized with hexokinase I in caveolae microdomains of rat spermatogenic cells. Journal of Cellular Physiology 207 397-406.

Reynolds ES 1963 The use of lead citrate at high $\mathrm{pH}$ as an electronopaque stain in electron microscopy. Journal of Cell Biology 17 208-212.

Rigau T, Rivera M, Palomo MJ, Fernandez-Novell JM, Mogas T, Ballester J, Peña A, Otaegui PJ, Guinovart JJ \& Rodriguez-Gil JE 2002 Differential effects of glucose and fructose on hexose metabolism in dog spermatozoa. Reproduction 123 579-591.

Sancho S, Pinart E, Briz M, Garcia-Gil N, Badia E, Bassols J, Kadar E, Pruneda A, Bussalleu E, Yeste M, Coll MG \& Bonet S 2004 Semen quality of postpubertal boars during increasing and decreasing natural photoperiods. Theriogenology 62 1271-1282.

Sancho S, Rodriguez-Gil JE, Pinart E, Briz M, Garcia-Gil N, Badia E, Bassols J, Pruneda A, Bussalleu E, Yeste M, Casas I, Palomo MJ, Ramió L \& Bonet S 2006 Effects of exposing boars to different artificial light regimens on semen plasma markers and in vivo fertilizing capacity. Theriogenology 20 317-331.

Saravia F, Wallgren M, Nagy S, Johannisson A \& Rodriguez-Martinez H 2005 Deep freezing of concentrated boar semen for intra-uterine insemination: effects on sperm viability. Theriogenology 63 1320-1333.

Setchell BP, Maddocks SI \& Brooks DE 1994 Anatomy, vasculature, inervation and fluids of the male reproductive tracts. In The Physiology of Reproduction, pp 1063-1076. Eds E Knobil \& JD Neill. New York: Raven Press.

Silva PF \& Gadella BM 2006 Detection of damage in mammalian sperm cells. Theriogenology 65 958-978.

Songsasen N \& Leibo SP 1997a Cryopreservation of mouse spermatozoa. I. Effect of seeding on fertilizing ability of cryopreserved spermatozoa. Cryobiology 35 240-254. 
Songsasen N \& Leibo SP 1997b Cryopreservation of mouse spermatozoa. II. Relationship between survival after cryopreservation and osmotic tolerance of spermatozoa from three strains of mice. Cryobiology 35 255-269.

Verheyen G, Pletincx I \& van Steirteghem A 1993 Effect of freezing method, thawing temperature and post-thaw dilution/washing on motility (CASA) and morphology characteristics of high quality human sperm. Human Reproduction 8 1678-1684.

Watson PF 1995 Recent developments and concepts in the cryopreservation of spermatozoa and the assessment of their post-thawing function. Reproduction, Fertility, and Development 7 871-891.

Watson PF, Morris GJ \& Clarke A 1981 Effect of Low Temperatures on Biological Membranes, London: Academic Press.
Westendorf P, Richter L \& Treu H 1975 Zur Tiefgefrierung von Ebersperma. Labor- und Besamungsergebnisse mit dem Hulsenberger Pailletten-verfahren. Deutsche Tierärzliche Wochenschrift $\mathbf{8 2}$ 261-267.

Wongtawan T, Saravia F, Wallgren M, Caballero I \& RodriguezMartinez H 2006 Fertility after deep intra-uterine artificial insemination of concentrated low-volume boar semen doses. Theriogenology 65 773-787.

Received 12 March 2007

First decision 2 April 2007

Accepted 2 April 2007 